\title{
Hermida del Llano, Cristina. La mutilación genital femenina. El declive de los mitos de legitimación. Valencia, Tirant lo Blanch 2017.
}

\author{
Aurelio de Prada \\ Área de Filosofía del Derecho \\ Universidad Rey Juan Carlos
}

Fecha de recepción 25/06/2018 I De publicación: 24/12/2018

A la vista del título de la monografía de la profesora Cristina Hermida del Llano, Titular de Filosofía del Derecho en la Universidad Rey Juan Carlos, pudiera pensarse que estamos ante un trabajo meramente descriptivo, -aséptico hasta donde fuera posible-, en el que, tras definir qué se entiende por mutilación genital femenina (MGF) se vendría a poner de relieve desde un punto de vista "objetivo", el declive de los mitos que legitiman dicha práctica.

Ahora bien, esa primera impresión se revela inmediatamente errónea con la lectura de la dedicatoria de la obra: “A todas las niñas y mujeres que han sido víctimas de esta brutal tradición” en la que el calificativo "brutal" muestra bien a las claras que la autora toma partido en contra de esa "tradición ancestral" como ella misma poco después la califica y que, según la OMS, han sufrido 200 millones de mujeres y niñas, siendo sometidas a ella 2 millones de niñas y adolescentes cada año.

Una toma de postura que no es, por lo demás, sino consecuencia de la concepción activa,- por así decirlo-, de la filosofía del derecho que defiende la profesora Hermida y es que, literalmente, "los filósofos del derecho no podemos permanecer callados ante casos como éste..." sino que hemos de trabajar en "aras de su erradicación."

Obviamente esa concepción activa, -militante si se prefiere-, de la filosofía del derecho no excluye sino todo lo contrario, la previa labor de elucidación intelectual. Cosa a la que la autora procede en el primer capítulo del texto "El relativismo cultural: Mitos de legitimación de la mutilación genital femenina." Y así, tras adoptar, en el apartado primero de dicho capítulo, "Aproximación conceptual a la mutilación genital femenina”, la definición de la OMS según la cual la MGF es la eliminación total o parcial de los genitales femeninos externos u otras lesiones en los mismos órganos por razones culturales o religiosas o por otros motivos no terapéuticos, pone de relieve, en el segundo apartado, "El relativismo cultural” que la MGF no sería sino un caso concreto del problema general que plantea 
el multiculturalismo en la sociedad contemporánea, en "el proceso actual de globalización y homogeneización de la comunidad mundial", por decirlo de nuevo con sus propias palabras.

En otros términos, la profesora Hermida es plenamente consciente, y así lo pone de relieve, de que, aunque se califique la MGF de "brutal" y "terrible", estamos ante una tradición ancestral susceptible, por ello mismo, de ser defendida desde el punto de vista de un relativismo cultural que sostenga que no hay una verdad universal y, en consecuencia, legitime las diferencias culturales. La autora, por el contrario, se decanta por el universalismo de los Derechos Humanos al considerar, literalmente, un error pensar que cada cultura merece ser respetada y protegida por expresar una manera única de ser, tanto de los individuos como de los colectivos, y es que tras ese conjunto de prácticas legitimadoras puede producirse una flagrante violación de los derechos humanos injustificable como sería el caso de la MGF.

Desde luego, esa toma de partido por el universalismo no impide a la profesora Hermida analizar en el siguiente apartado de este capítulo "Los mitos de legitimación", las razones desde las que se pretende justificar la MGF. Razones de diferentes tipos: de índole sexual y reproductiva, de estética o belleza, de purificación, religiosas y socioculturales que son examinadas pormenorizadamente hasta llegar a la conclusión de que pueden reconducirse a una práctica social con un marcado componente identitario de pertenencia al grupo social que condiciona de un modo inevitable la efectiva integración de las mujeres en el grupo y sus expectativas de desarrollo personal.

En otros términos, lo que se esconde tras esos falsos mitos de legitimación, según la autora, es una soterrada finalidad de control de la sexualidad femenina, deliberadamente enmascarada bajo diversas razones de higiene, salud, estética, pureza o pretendidamente religiosas y con ello la subordinación clara de la mujer al varón, violándose el principio de igualdad de trato entre ambos.

El capítulo se cierra con un cuarto apartado "La mutilación genital femenina: Una tortura de por vida", en el que, apoyándose en el análisis de numerosas sentencias, defiende que la MGF puede equipararse a los tratos inhumanos o degradantes de modo que resulta imprescindible trabajar en dos áreas diferentes. Por un lado, tratando de evitar que la MGF se produzca, combatiéndola con las armas que brinda el estado de derecho y, por otro, dando un tratamiento clínico y apoyo psicológico adecuado a las mujeres que la han padecido. 
Como era de esperar, a la vista de lo anterior y habida cuenta de que la MGF sigue gozando de multitud de formas de legitimación y resulta respaldada social e incluso legalmente, los dos capítulos siguiente del libro se centran en el análisis de los medios legales que permiten combatir la MGF: los internacionales y europeos en el capítulo segundo y los nacionales en el tercero.

Y en efecto, dicho análisis comienza en el siguiente capítulo del texto, el segundo, "Legislación internacional y europea contra la mutilación genital femenina" con un primer apartado "Violación internacional de derechos humanos sí o sí", en el que se repasa el entramado normativo a nivel internacional desde la creación por parte de la ONU en 1946 de la Comisión de la Condición Jurídica y Social de la Mujer, encargada de redactar la primera Declaración sobre la Eliminación de la Discriminación contra la Mujer en 1967, hasta la adopción en 2012 por parte de la Asamblea General de Naciones Unidas de la primera resolución específica (A/RES/67/146) para la intensificación de los esfuerzos mundiales para la eliminación de la MGF, llegando a la conclusión de que la MGF constituye claramente una violación de los derechos humanos.

El apartado segundo de este capítulo, "La mutilación genital femenina como práctica tipificada en todos los Estados miembros de la Unión Europea”, prosigue con el análisis de las armas legales contra la MGF si bien al nivel de la UE. En él, tras señalar que el fenómeno de la mutilación genital femenina afectó a Europa debido fundamentalmente a la inmigración de personas procedentes de países donde sigue en vigor, se analizan en detalle diversas Resoluciones al respecto tanto del Consejo de Europa, cuanto del Parlamento Europeo, así como el art. 3 de la Carta de los Derechos Fundamentales de la Unión Europea de 2007 y la comunicación adoptada por la Comisión Europea en 2013: "Hacia la eliminación de la mutilación genital femenina."

Tal y como anticipábamos más arriba, el análisis de las armas legales a emplear en el combate contra la MGF prosigue en el capítulo tercero, "La mutilación genital femenina desde la perspectiva jurídica española.", ciñéndose exclusivamente a España. Y así, tras señalarse en el primer apartado "La concienciación social en España ante la mutilación genital femenina" cómo la opinión pública española se ha ido sensibilizando del tema a raíz de la llegada regular de inmigrantes de muy distintos orígenes que, por otro lado, han hecho que la población española sea más rica étnica y culturalmente, en el segundo "La respuesta del Legislador español frente a la mutilación genital femenina", se hace hincapié en que, a diferencia de otros países europeos que prefirieron no tipificarla como delito 
autónomo, en España, mediante la L.O. 11/2003 de 29 de septiembre se incorporó de forma explícita la MGF como delito autónomo con su tipificación en el artículo 149.2 del Código Penal; tipificación que ha de relacionarse con la llevada a cabo por la L.O. 3/2005 de 8 de julio, de modificación de la Ley Orgánica del Poder Judicial para perseguir extraterritorialmente la práctica de la mutilación genital femenina, añadiéndose un nuevo apartado g) al artículo 23.4 de la LOPJ. .

Ese artículo 149.2 del Código Penal es objeto de un análisis pormenorizado en el siguiente apartado de este capítulo "La tipificación de la mutilación genital femenina como delito de lesiones en el ámbito penal español", mientras que en el cuarto "La llegada de la mutilación genital femenina a España por vía jurisprudencial" a partir del análisis de numerosas sentencias se pone de relieve como la MGF llegó a España no sólo a través de los medios de comunicación sino también por medio de fallos judiciales. Finalmente en el apartado quinto, "La regulación jurídica de la mutilación genital femenina en el ámbito de las comunidades autónomas" se analiza in extenso la regulación jurídica autonómica relativa a la MGF.

Dentro de la misma perspectiva de combatir la MGF con las armas legales, en el capítulo cuarto " $E l$ derecho de asilo en España y en la Unión Europea ante los casos de mutilación genital femenina. La cuestión de género.", se aborda una posible interpretación de la definición de refugiado plasmada en la Convención de Ginebra y ello desde una perspectiva de género que incluiría la MGF. Y así en el apartado primero, "El derecho de asilo. La cuestión de género.", se analizan los problemas que plantea el hecho de que la Convención de Ginebra se concibiera para proteger a un tipo muy específico de refugiados, los procedentes de la Europa socialista que huían de una persecución política y que, en último término, abonarían la necesidad de tal nueva interpretación.

En el apartado segundo "El derecho de asilo en la Unión Europea.", tras aludirse a diversas estadísticas sobre el número de mujeres y niñas procedentes de países donde se practica la MGF, se hace especial hincapié en la Sentencia del Tribunal de Justicia de la Unión Europea de 26 de febrero de 2015, c 47213 en relación al concepto de "refugiado". Finalmente en el apartado tercero "El derecho de asilo en España.", se señala que España se ha sumado a la interpretación de la Convención de Ginebra en materia del agente perseguidor con una pionera concesión de asilo a una víctima de violencia intrafamiliar en su país de origen, reconociendo que la persecución realizada por un agente no estatal 
en el ámbito privado tenía repercusión en el ámbito público con el reconocimiento de la condición de refugiada.

Cabría pensar que con este examen de las armas legales disponibles para el combate contra la MGF se cerraría el libro pero la autora aún añade un quinto capítulo "Retos pendientes frente a la mutilación genital femenina." en el que se analizan los retos que tenemos aún para tratar de prevenir, castigar y abolir la MGF; retos que conforman los sucesivos apartados del capítulo y que se concretan en "Aprender a gestionar los conflictos generados por el multiculturalismo. "No" al relativismo cultural o moral.", "La conquista de un certero examen de juicio de culpabilidad.", "La mejora de los profesionales de la salud y los centros de acogida.", "La destrucción de prejuicios y estereotipos sociales.", "El apoyo a las campañas de información y sensibilización social realizadas por asociaciones y ONG's en la comunidad para generar un cambio social." y "La educación en valores."

El libro termina con una "Conclusiones finales" en las que la profesora Hermida expresa su deseo de que su texto contribuya a que la MGF no se entienda como "cultura" sino como "mutilación" y violación de los derechos de las mujeres, discriminación femenina y asimismo a que aliente a la Comisión Europea a la adopción de unas directrices interpretativas sobre la MGF y el asilo que permitan a los Estados miembros armonizar mejor las prácticas nacionales de conformidad con el espíritu del Sistema Europeo Común de Asilo (SECA).

En resumen, un "escrito de combate", -si se nos permite utilizar la expresión-, contra la MGF desde una concepción activa de la filosofía del derecho que ciertamente da noticia de las armas legales disponibles, hoy por hoy, para esa lucha incluyendo una selección jurisprudencial sobre mutilación genital femenina en España. Un texto, por tanto, sumamente útil para todos los que consideramos con la profesora Hermida que la MGF es una práctica brutal y defendemos asimismo dicha concepción activa de la filosofía del derecho. 